Copyright (C) 2016 by Academic Publishing House Researcher

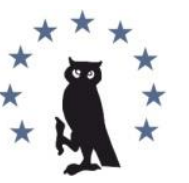

Published in the Russian Federation

European Researcher

Has been issued since 2010.

ISSN 2219-8229

E-ISSN 2224-0136

Vol. 104, Is. 3, pp. 178-183, 2016

DOI: 10.13187/er.2016.104.178

www.erjournal.ru

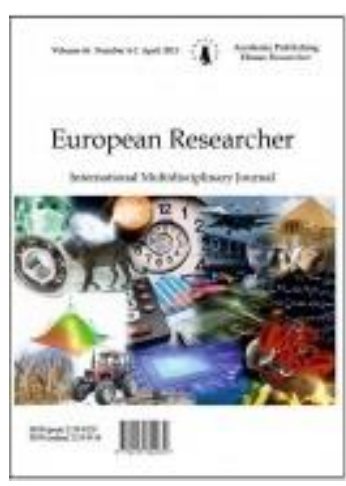

UDC 338

\title{
Internal Resources to Improve the Quality of Higher Education
}

\author{
Tatyana V. Zak
}

Astrakhan state university, Russian Federation

$\mathrm{PhD}$, Associate Professor

E-mail: tvzak18@inbox.ru

\section{Abstract}

The article deals with the situation in the Russian higher education system. The factors affecting the improvement of the quality of higher education are analyzed. The emphasis is on mass universities. The main obstacles to improving the quality of education in these institutions are the Institute of collective reputation and the high costs of the struggle for improving the quality of education. The necessity of focusing on the actuation of the internal resources to improve the quality associated with the change in the educational process: giving students the right to choose the timing exams and training period at university. The implementation of the proposed measures will reduce the opportunity costs associated with quality improvement activities. The proposed change in the organization of the learning process opens the possibility to estimate the activity of universities in terms of medium-term implementation of educational programs. The use of this indicator will not only combine the two different targets of universities, but also to minimize the costs of opportunistic behavior of teachers and management.

Keywords: internal resources, external resources, collective reputation, opportunistic behavior, credence goods, the average duration of study, technology of the educational process

\section{Введение}

Состояние системы высшего образования, особенно положение, сложившееся в большинстве университетов массового сектора, вызывает беспокойство и тревогу не только у участников образовательного процесса, но и у широкой общественности, родителей, органов государственной власти, самих студентов. Многочисленные попытки структур, регулирующих и контролирующих деятельность образовательных организаций в сфере высшего образования, направленные на повышение качества высшего образования в России, не приносят ожидаемого результата. В связи с этим ученые разных стран обосновывают необходимость дальнейшего реформирования системы высшего образования. При этом не всегда учитываются сложившиеся экономические и политические условия, выступающие в качестве ограничителей предлагаемых программ. Нам представляется, что на современном этапе главную роль в повышении эффективности образовательного процесса могут и должны сыграть внутренние резервы системы высшего образования. 


\section{Материалы и методы}

Материалами для написания статьи послужили статистические данные, представленные в изданиях Росстата, Научно- исследовательского университета - Высшей школы экономики, публикации российских и зарубежных авторов.

В работе использованы методы статистического анализа, сравнительного анализа, а также ситуационного анализа, который предполагает оценку эффективности проектов реформирования высшей школы в контексте сложившейся социально- экономической ситуации.

\section{Обсуждение}

Проблема качества высшего образования исследуется многими учеными: А. Алпатовым [1], Е. Балацким [2], М. Бляхером [3], Т. Клячко [4] , Э. Де Корте [5], Э. Ливни, Я. Кузьминовым, В. Мау, Л. Полищуком [6], И. Рождественской, В. Тамбовцевым [7], Н. Форратом [8] и др.

\section{Результаты}

В последние десятилетия в системе высшего образования России произошли существенные изменения. Прежде всего, сделаны определенные шаги по пути приватизации высшей школы, что выразилось в появлении негосударственных (частных) вузов, а также студентов, обучающихся с полным возмещением затрат. Кроме того, существенно увеличилось количество университетов и численность студентов.

Действительно, за период с 1990 по 2015 гг. количество образовательных организаций высшего образования увеличилось в нашей стране в 1,8 раза: с 514 до 950, при этом с 2011 года наметилась тенденция некоторого уменьшения количества вузов. За это время количество студентов, приходившихся на 10 тыс. человек населения, увеличилось в 1,9 раза: со 190 до 356, причем с 2011 года так же наблюдается тенденция к уменьшению данного показателя (см. табл.). В результате уровень образования населения в возрасте 15 лет и старше увеличился со 162 человек в расчете на 1000 человек населения данного возраста в 2002 году до 234 человек в 2010 году [9, с. 11].

Существенное изменение претерпели и источники финансирования высшей школы: в 2013 году 61,1 \% всех студентов, занимающихся по программам бакалавриата, специалитета и магистратуры, обучались за счет внебюджетных средств [10, с. 45]. В течение рассматриваемого периода времени произошло увеличение доли студентов, обучающихся на заочных и очно-заочных отделениях.

Таблица 1

Развитие системы высшего образования в России в 1990-2015 гг.

\begin{tabular}{|l|l|l|l|l|}
\hline Годы & $\begin{array}{l}\text { Число } \\
\text { образовательных } \\
\text { организаций }\end{array}$ & $\begin{array}{l}\text { В них студентов - } \\
\text { всего, тыс. чел. }\end{array}$ & $\begin{array}{l}\text { Доля студентов, } \\
\text { обучающихся } \\
\text { на заочных и } \\
\text { вечерних } \\
\text { отделениях, \% }\end{array}$ & $\begin{array}{l}\text { иа тыс. } \\
\text { человек } \\
\text { населения } \\
\text { приходилось } \\
\text { студентов }\end{array}$ \\
\hline $1990 / 91$ & 514 & 2824,5 & 41,7 & 190 \\
\hline $2005 / 06$ & 1068 & 7064,7 & 48,2 & 493 \\
\hline $2010 / 11$ & 1115 & 7049,8 & 54,4 & 493 \\
\hline $2013 / 14$ & 969 & 5646,7 & 52,6 & 393 \\
\hline $2014 / 15$ & 950 & 5209 & 50,6 & 356 \\
\hline
\end{tabular}

1)Рассчитано по [11, с. 207].

Происшедшие изменения не могли не сказаться на качестве высшего образования. Вопрос о качестве, его изменении в связи с увеличением доступности является предметом обсуждения не только ученых, но и представителей государственных структур, широкой общественности, непосредственных участников образовательного процесса. Большинство участников дискуссий склоняются к выводу о том, что, хотя однозначно измерить и оценить 
качество, его динамику очень сложно, российская высшая школа переживает не лучшие времена [12].

Для подтверждения данного положения используются косвенные показатели: уменьшение требований университетов к результатам освоения студентами учебной программы; увеличение количества студентов, совмещающих учебу с работой; широкое распространение заочной формы обучения.

Многочисленные усилия, направленные на повышение качества высшего образования, предпринимаемые на разных уровнях, не только не приводят к желаемым результатам, но часто оказывают обратное воздействие. Причины неудач в реформировании системы высшего образования трактуются по-разному. Некоторые исследователи источник зла видят в системе платного обучения, использование которого привело к существенному увеличению количества студентов и, соответственно, не могло не сказаться на качестве высшего образования. Другие связывают данное обстоятельство с особенностью конкуренции на рынке доверительных благ, к которым относятся образовательные услуги [13].

Еще одна группа исследователей низкое качество образования связывает с чрезмерным регулированием (гиперрегулированием) системы высшего образования государством, Закручивание гаек, происходящее в системе высшего образования, привело к разбуханию административно- управленческого персонала вузов, сокращению численности профессорско-преподавательского персонала, снижению реальной заработной платы преподавателей, как ответной, защитной реакции вузовского сообщества на усиление государственного регулирования [14].

В последние годы все большее распространение получает концепция, в соответствии с которой обеспечить повышение качества высшего образования невозможно без проведения согласованных реформ в высшей школе, науке и промышленном секторе экономики [15].

Действительно, многие проблемы, с которыми сегодня сталкивается система высшего образования, могут быть решены только вкупе с реформированием всех секторов: науки, реального сектора экономики, общего образования, системы государственного управления. Необходимым условием повышения качества высшего образования является модернизация экономики. Однако решение этой проблемы сталкивается с целым рядом не только экономических, но и политических ограничителей [16]. Все это обусловливает необходимость концентрации усилий на создании условий для реализации внутренних резервов системы высшего образования.

Создание условий для реализации этих факторов поможет реальному реформированию, прежде всего, в секторе массового высшего образования, поставляющем значительную долю образовательного продукта низкого качества.

Более низкое качество образования в массовых вузах обусловлено не только тем, что, в отличие от элитных вузов, они не могут осуществлять процедуру отбора будущих студентов на входе, но и тем, что они не могут позволить производить отсев уже поступивших студентов.

Отсутствие мотивации к повышению качества образования у массовых вузов в значительной степени обусловлено сложившейся коллективной репутацией этих университетов [17], которая по существу является для них институциональной ловушкой. Именно репутация «одинаковости» создает для университетов этого сектора барьер, ограничивающий их стремление к повышению эффективности образовательного процесса.

Для того, чтобы «заработать» собственную, отличную от коллективной, репутацию, вузу необходимо заплатить высокую цену, которая определяется издержками упущенных возможностей включения в борьбу за повышение эффективности образовательного процесса. Невозможно повысить качество образования, не отказавшись от системы заниженных требований к результатам освоения студентами учебной программы.

Повышение же требований к результатам усвоения образовательных программ в условиях существующей технологии организации учебного процесса не может не привести к увеличению количества отчисляемых студентов.

Для вуза, вступившего в борьбу за повышение качества образования, величина потерь складывается из:

- неполученной платы за обучение отчисленных за неуспеваемость студентов, обучающихся с полным возмещением затрат, 
- бюджетных средств, неполученных за отчисленных студентов-бюджетников,

- неполученных средств от потенциальных студентов, поступающих ради подачи сигнала на рынке труда.

Ситуация осложняется тем, что борьба за качество ведет к снижению доходов уже сегодня и лишь с некоторой вероятностью может привести к увеличению доходов в будущем.

Нам представляется, что одним из основных факторов, способствующих снижению стоимости борьбы за повышение качества образования, является изменение технологии организации учебного процесса, в частности, отказ от:

- системы обучения студентов на основе формирования постоянно действующих учебных групп для изучения всех дисциплин, предусмотренных учебным планом;

- установления единых сроков сдачи экзаменов для группы (курса), независимо от индивидуальных способностей студентов и времени, необходимого для освоения изучаемого материала разными студентами;

- коллективного перевода всех студентов в конце каждого учебного года на следующий курс;

- отчисления из университета в случае не ликвидации задолженностей по дисциплинам учебного плана в течение установленного периода времени.

Однако признание за студентами права самостоятельно определять сроки освоения учебной программы приведет к необходимости изменения условий финансирования образовательных услуг. В частности, потребуется установить плату за сверхнормативный срок обучения для всех студентов, в том числе обучающихся за счет средств государственного бюджета. Отметим, что данное изменение позволит сократить необоснованный разрыв в издержках обучения двух категорий студентов.

Технология организации учебного процесса, способствующая снижению оппортунистического поведения студентов и преподавателей, связана с переходом к обучению по индивидуальным планам. Для студентов, обучающихся с полным возмещением затрат, общая стоимость обучения в вузе должна зависеть от фактического периода обучения. Что касается бюджетных студентов, они должны получить право на финансирование за счет средств государственного бюджета только в течение законодательно установленного срока обучения.

Введение данной инновации создаст стимулы к более продуктивной деятельности для всех субъектов образовательного процесса:

- для студентов - уложиться в установленные сроки освоения программы, что в сочетании с новой системой организации учебного процесса заставит их лучше учиться и будет способствовать повышению качества образования

- для университетов - к более объективной оценке знаний студентов, поскольку, с одной стороны, завышение оценок приведет к искусственному занижению периода обучения и, соответственно, к сокращению доходов вуза; а, с другой стороны, получение неудовлетворительных оценок не повлечет за собой отчисление студентов.

\section{Заключение}

Двойственность целей некоммерческой организации, к которой относится университет, обусловливает ее направленность, во-первых, на выполнение провозглашенной миссии и, во-вторых, на получение доходов от учебной, научной и предпринимательской деятельности. В связи с этим представляется целесообразным оценивать непосредственный результат деятельности вуза с помощью показателя, достижение которого способствует одновременной «работе» на обе цели.

В условиях использования новой технологи организации учебного процесса таким показателем может стать средний фактический срок обучения в университете по всем образовательным программам.

Безусловно, предоставление вузам самостоятельности в организации учебного процесса, и, в частности, возможности не отчислять студентов, имеющих академические задолженности, а также признание за студентами права выбирать срок получения образования при условии оплаты ими сверхнормативного периода, независимо от формы 
обучения, не приведет к устранению оппортунистического поведения. Однако данная инновация создаст условия для его минимизации.

К тому же использование показателя среднего срока обучения в университете для оценки качества образовательного процесса будет способствовать снижению вероятности оппортунистического поведения университетов, направленного на искусственное завышение сроков обучения с целью получения дополнительного дохода.

\section{Примечания:}

1. Алпатов А.О. Согласованности реформ в высшей школе, науке и промышленном секторе экономики / А. Алпатов // Экономическая политика. 2014. № 4. С. 153-176.

2. Балацкий Е. Управленческие парадоксы реформ в университетском секторе / Е. Алпатов // Журнал Новой Экономической Ассоциации. 2015. №2. С.б124-149.

3. Бляхер М. Гиперрегулирование в системе высшего образования / М. Бляхер // Отечественные записки. 2013. № 4 .

4. Клячко Т.Л. Тенденции развития высшего профессионального образования в Российской Федерации. / Т.Л. Клячко, В.А. Мау // Вопросы образования. 2007. №3. С. 47-63.

5. Де Корте Э. Анализ деятельности университетов Западной Европы: от оценки качества до аккредитации / Эрик де Корте // Вопросы образования. 2014. №4. С. 36-55.

6. Полищук Л. Качество высшего образования в России: роль конкуренции и рынка труда / Л. Полищук, Э. Ливни // Вопросы образования. 2005. № 1. С. 70-85.

7. Тамбовцев В. Реформа высшего образования в России: международный опыт и экономическая теория / В. Тамбовцев, И. Рождественская // Вопросы экономики. 2014. № 5 . C. $97-108$.

8. Форрат Н.В. Проблема качества высшего образования: мировые вызовы и их российские трансформации / Н.В. Форрат // Вопросы образования. 2009. №1. С. 121-138.

9. Образование в цифрах: краткий статистический сборник. М.: Нац. исслед. ун-т Высшая школа экономики. 2014. 80 с.

10. Образование в цифрах: краткий статистический сборник. М.: Нац. исслед. ун-т Высшая школа экономики. 2014. 80 с.

11. Российский статистический ежегодник. 2015. Стат. сб. М. 2015. 728 с.

12. Зак Т.В. Образовательный процесс и экономическая политика государства / Т.В.Зак. // Вестник Астраханского государственного технического университета. Сер. экономика. 2010. № 2. С. 36-43.

13. Тамбовцев В. Реформа высшего образования в России: международный опыт и экономическая теория / В. Тамбовцев, И. Рождественская // Вопросы экономики. 2014. № 5. C. 97-108.

14. Бляхер М. Гиперрегулирование в системе высшего образования. / М. Бляхер // Отечественные записки. 2013. № 4.

15. Алпатов А.О согласованности реформ в высшей школе, науке и промышленном секторе экономики / А. Алпатов. // Экономическая политика. 2014. № 4. С. 153-176.

16. Урнов М.Ю. Политические ограничители модернизации российской экономики / Урнов М.Ю. // Журнал Новой экономической ассоциации. 2015. №3 (27). С. 183-188.

17. Полищук Л.И. Коллективная репутация в высшей школе: анализ равновесной модели / Полищук Л.И. // Журнал Новой экономической ассоциации. 2010. №7. С. 46-69.

\section{References}

1. Alpatov A.O. Soglasovannosti reform v vysshei shkole, nauke i promyshlennom sektore ekonomiki / A. Alpatov // Ekonomicheskaya politika. 2014. № 4. S. 153-176.

2. Balatskii E. Upravlencheskie paradoksy reform v universitetskom sektore / E. Alpatov // Zhurnal Novoi Ekonomicheskoi Assotsiatsii. 2015. №2. S.b124-149.

3. Blyakher M. Giperregulirovanie v sisteme vysshego obrazovaniya / M. Blyakher // Otechestvennye zapiski. 2013. № 4 .

4. Klyachko T.L. Tendentsii razvitiya vysshego professional'nogo obrazovaniya v Rossiiskoi Federatsii. / T.L. Klyachko, V.A. Mau // Voprosy obrazovaniya. 2007. №3. S. 47-63.

5. De Korte E. Analiz deyatel'nosti universitetov Zapadnoi Evropy: ot otsenki kachestva do akkreditatsii / Erik de Korte // Voprosy obrazovaniya. 2014. №4. S. 36-55. 
6. Polishchuk L. Kachestvo vysshego obrazovaniya v Rossii: rol' konkurentsii i rynka truda / L. Polishchuk, E. Livni // Voprosy obrazovaniya. 2005. № 1. S. 70-85.

7. Tambovtsev V. Reforma vysshego obrazovaniya v Rossii: mezhdunarodnyi opyt i ekonomicheskaya teoriya / V. Tambovtsev, I. Rozhdestvenskaya // Voprosy ekonomiki. 2014. № 5. S. 97-108.

8. Forrat N.V. Problema kachestva vysshego obrazovaniya: mirovye vyzovy i ikh rossiiskie transformatsii / N.V. Forrat // Voprosy obrazovaniya. 2009. №1. S. 121-138.

9. Obrazovanie $\mathrm{v}$ tsifrakh: kratkii statisticheskii sbornik. M.: Nats. issled. un-t Vysshaya shkola ekonomiki. 2014. $80 \mathrm{~s}$.

10. Obrazovanie v tsifrakh: kratkii statisticheskii sbornik. M.: Nats. issled. un-t Vysshaya shkola ekonomiki. 2014. $80 \mathrm{~s}$.

11. Rossiiskii statisticheskii ezhegodnik. 2015. Stat. sb. M. 2015. 728 s.

12. Zak T.V. Obrazovatel'nyi protsess i ekonomicheskaya politika gosudarstva / T.V. Zak. // Vestnik Astrakhanskogo gosudarstvennogo tekhnicheskogo universiteta. Ser. ekonomika. 2010. № 2. S. 36-43.

13. Tambovtsev V. Reforma vysshego obrazovaniya v Rossii: mezhdunarodnyi opyt i ekonomicheskaya teoriya / V. Tambovtsev, I. Rozhdestvenskaya // Voprosy ekonomiki. 2014. № 5 . S. 97-108.

14. Blyakher M. Giperregulirovanie v sisteme vysshego obrazovaniya. / M. Blyakher // Otechestvennye zapiski. 2013. № 4 .

15. Alpatov A.O soglasovannosti reform v vysshei shkole, nauke i promyshlennom sektore ekonomiki / A. Alpatov. // Ekonomicheskaya politika. 2014. № 4. S. 153-176.

16. Urnov M.Yu. Politicheskie ogranichiteli modernizatsii rossiiskoi ekonomiki / Urnov M.Yu. // Zhurnal Novoi ekonomicheskoi assotsiatsii. 2015. №3 (27). S. 183-188.

17. Polishchuk L.I. Kollektivnaya reputatsiya v vysshei shkole: analiz ravnovesnoi modeli / Polishchuk L.I. // Zhurnal Novoi ekonomicheskoi assotsiatsii. 2010. № 7. S. 46-69.

УДК 338

\section{Внутренние резервы повышения качества высшего образования в России}

Татьяна Владимировна Зак

Астраханский государственный университет, Российская Федерация

Кандидат экономических наук, доцент

E-mail: tvzak18@inbox.ru

Аннотация. В статье рассматривается ситуация, сложившаяся в системе высшего образования в России. Выявляются факторы, препятствующие повышению качества высшего образования. При этом акцент делается на массовых университетах. Главными препятствиями для повышения качества в этих образовательных организациях являются институт коллективной репутации и высокие издержки борьбы за повышение качества образования. Обосновывается необходимость концентрации усилий на приведении в действие внутренних резервов повышения качества: изменении организации учебного процесса, предоставлении студентам права выбора сроков сдачи экзаменов и периода обучения в университете. Реализация предложенных мер приведет к снижению альтернативных издержек, связанных $\mathrm{c}$ деятельностью по повышению качества. Предлагаемые изменения в организации процесса обучения открывают возможность для оценивания деятельности университетов по показателю среднего срока освоения учебных программ студентами. Использование данного показателя позволит не только совместить две разных цели университетов, но и минимизировать издержки оппортунистического поведения преподавателей и менеджмента.

Ключевые слова: внутренние резервы, внешние факторы, коллективная репутация, оппортунистическое поведение, доверительные блага, средний срок обучения, технология учебного процесса. 